\title{
Representações sobre 0 uso de álcool por mulheres em tratamento em um centro de referência da cidade de São Paulo - Brasil
}

\author{
Edemilson Antunes de Campos
} Jéssica Gallante Reis ${ }^{2}$

CAMPOS, E.A.; REIS, J.G. Representations on the use of alcohol among women undergoing treatment at a reference center in the city of São Paulo, Brazil. Interface Comunic., Saude, Educ., v.14, n.34, p.539-50, jul./set. 2010.

The objective of this study was to understand the representations and meanings elaborated regarding the use of alcohol among women undergoing treatment at the Reference Center for Alcohol, Tobacco and Other Drugs (CRATOD), located in the city of São Paulo, Brazil. For this, semi-structured interviews were conducted with women who were making what was considered abusive use of alcohol. For these women, their representations on the use of alcohol were linked to their family, professional and gender relationships, which defined the conceptual ways of classifying alcohol use, either as socially accepted or as abusive. Through this route, a system of accusations came into action, involving the particular values of the sociocultural scenario to which they belonged, thereby identifying them as "women who abuse alcohol", i.e. women who do not fulfill their social obligations within the spheres of the family and work.

Keywords: Female alcoholism. Gender. Social representations. Alcohol abuse.
O objetivo deste trabalho foi compreender as representações e os significados elaborados sobre o uso de álcool por mulheres em tratamento no Centro de Referência de Álcool, Tabaco e Outras Drogas (CRATOD), localizado na cidade de São Paulo-Brasil. Para tanto, realizaramse entrevistas semiestruturadas com mulheres que fazem uso considerado abusivo de álcool. Para essas mulheres, as representações sobre o uso do álcool estão ligadas às relações familiares, profissionais e de gênero, que definem os modos de classificação do uso do álcool concebidos como socialmente aceito e como abusivo e, por essa via, acionam um sistema de acusações, que envolve os valores próprios do universo sociocultural no qual estão inseridas, identificando-as como "mulheres que abusam do álcool", isto é, mulheres que não cumprem suas obrigações sociais nas esferas da família e do trabalho.

Palavras-chave: Alcoolismo feminino. Gênero. Representações sociais. Uso abusivo de álcool.
"Artigo inédito, elaborado com base em Reis (2009): pesquisa do Programa Institucional de Bolsas de Iniciação Científica, financiada pelo CNPq e aprovada pelo Comitê de Ética em Pesquisa da Escola de Enfermagem da Universidade de São Paulo.

${ }^{1}$ Escola de Artes, Ciências e Humanidades, Universidade de São Paulo (USP). Rua Arlindo Bettio, 1000, Ermelino Matarazzo. São Paulo SP, Brasil. 03.828-000 edicampos@usp.br

2 Graduanda em Obstetrícia, Escola de Artes, Ciências e Humanidades, USP 


\section{Introdução}

A ingestão de bebidas alcoólicas é parte integrante da vida social, operando como um importante marcador das relações sociais, dos espaços de sociabilidade, da experiência corporal, da saúde e da doença.

$\mathrm{O}$ ato de beber com os amigos no bar, após o trabalho ou nas ocasiões festivas, por exemplo, demarca periodização do tempo e do espaço sociais trabalho/lazer e trabalho/casa -, definindo os espaços nos quais o uso do álcool é aceitável e possível. Nessa linha, todo o discurso sobre o álcool é também um discurso sobre a sociedade (Ancel, Gaussot, 1998).

Em cada sociedade, encontramos padrões construídos e institucionalizados de uso das bebidas alcoólicas e uma variedade de motivos e de oportunidades construídas para o ato de beber. $O$ ato de beber é, portanto, um ato social, que sinaliza para os contextos possíveis, nos quais o uso do álcool é valorizado (Neves, 2004).

A ingestão de bebidas alcoólicas é, assim, regida por regras e normas, definindo as formas de classificação do uso do álcool em: "abusivo", "patológico", "alcoolismo", "alcoolização", "dependência", "embriaguez" etc.

É nessa linha que Souza e Garnelo (2006) enfatizam um modelo para a compreensão do uso do álcool, destacando sua definição em diferentes contextos de análise. Esses autores destacam: 1 a noção de "dependência ao álcool", entendida como o conceito mais restrito, aparecendo associado ao modelo biomédico; 2 a noção de "problemas relacionados ao uso do álcool", cujo alcance é mais amplo que o da anterior, e abrange os problemas sociais e de saúde relacionados ao uso de bebidas alcoólicas, contextualizados em seu espaço social, cultural e histórico, e 3 o conceito de "alcoolização" ${ }^{3}$, que engloba os anteriores, e é próprio ao campo de estudos das ciências humanas e sociais, associando o uso do álcool aos significados que o ato de beber assume em um determinado contexto cultural, independente de ser ou não concebido como problema.

A noção de "dependência do álcool" remete, fundamentalmente, a uma perspectiva substantivista, de modo que a dependência segue uma progressão linear (Vaillant, 1999; Jelinek, 1960). Já as pesquisas desenvolvidas no campo das ciências humanas e sociais, apontam para a intermitência dos estados de alcoolização observados, relativizando os padrões de regularidade e estabilidade preconizados pela noção de dependência, contribuindo para dessubstancializar o conceito de alcoolismo, remetendo-o ao contexto sociocultural no qual o uso do álcool está inserido (Fainzang, 2007, 1996; Campos, 2005, 2004).

É seguindo essa linha que, neste artigo, pretendemos abordar o tema do "alcoolismo feminino", a partir das representações de mulheres que fazem um uso considerado abusivo de álcool.

Nas últimas décadas, as autoridades médicas e sanitárias têm apontado o aumento de casos de "dependência do álcool" entre mulheres. Essa questão também tem chamado a atenção da mídia impressa preocupada em abordar o problema do "alcoolismo feminino" 4 .

Segundo dados do II Levantamento Domiciliar sobre o Uso de Drogas Psicotrópicas no Brasil, realizado em 2005, pelo Centro Brasileiro de Informações sobre Drogas Psicotrópicas (CEBRID), da Universidade Federal de São Paulo (Unifesp), em conjunto com a Secretaria Nacional Anti Drogas (SENAD), envolvendo as 108 maiores cidades do País, 6,9\% das mulheres brasileiras são dependentes do álcool (Carlini et al., 2006).

De acordo com a Secretaria de Estado da Saúde de São Paulo, cerca de três mil mulheres recorrem todo ano aos 47 Centros de Atenção Psicossocial (CAPs) para tratamento da dependência do álcool ${ }^{5}$.

\footnotetext{
${ }^{3}$ A noção de alcoolização

é retomada aqui no sentido conceituado por Menéndez (1982, p.63), isto é, "como o conjunto de funções e consequências positivas e negativas relacionadas à ingesta de álcool em conjuntos sociais estratificados, e não apenas o estudo dos alcoólicos dependentes, nem os excessivos, nem os moderados, mas sim o processo que inclui todos e que evita considerar o problema em termos de saúde e/ou enfermidade mental".

${ }^{4}$ Destaca-se, nessa linha, a reportagem de Lopes e Magalhães (2009).

${ }^{5}$ Notícia publicada no site da Secretaria de Estado da Saúde de São Paulo, em 27 mar. 2009 , sob o título: Mulheres estudadas e

ricas procuram o SUS para tratamento do alcoolismo. Disponível em:

<http://www.saude sp.gov.br/content/ phewespope.mmp> Acesso em: 10 set. 2009
} 
${ }^{6}$ Nessa perspectiva, ver o artigo do médico Drauzio Varella, publicado no Jornal Folha de São Paulo, intitulado "As mulheres e o álcool",

no qual afirma: "Apesar do empenho feminino em busca da igualdade, por um capricho da natureza, o metabolismo do álcool nas mulheres não é, nem jamais será igual ao nosso. [...] Esses mecanismos explicam porque ficam embriagadas com doses mais baixas e progridem mais rapidamente para o alcoolismo crônico e seu cortejo de complicações" (Varella, 2009, p.E14).
É assim que o uso considerado abusivo de álcool, pelas mulheres, é tratado com base em uma perspectiva médico-psiquiátrica, centrada nos "riscos" do uso do álcool, com ênfase nos aspectos fisiológicos e metabólicos que podem favorecer o desenvolvimento do alcoolismo feminino ${ }^{6}$.

Observa-se, assim, uma lacuna na análise das representações e dos significados construídos sobre o uso do álcool, bem como sobre o modo como o ato de beber articula-se às relações familiares e de gênero, nas quais as mulheres estão inseridas.

\section{A pesquisa em um centro de referência para o tratamento do alcoolismo}

Este estudo baseia-se em pesquisa realizada no período de abril a junho de 2009, no Centro de Referência de Álcool, Tabaco e Outras Drogas (CRATOD), com o objetivo de apreender as representações sobre o uso do álcool entre as mulheres em tratamento nesse centro de referência. O projeto de pesquisa foi submetido e aprovado pelo Comitê de Ética em Pesquisa da Escola de Enfermagem da Universidade de São Paulo (CEP/EEUSP).

Seguindo a linha aberta por Jodelet (2001), as representações sociais são entendidas aqui como "uma forma de conhecimento, socialmente elaborada e partilhada, com um objetivo prático, e que contribui para a construção de uma realidade comum a um conjunto social" (p.22).

As representações compõem os sistemas de interpretação social, possibilitando, aos indivíduos, formularem uma compreensão sobre a experiência vivida, orientando suas práticas sociais. Ora, as mulheres entrevistadas, quando falam do uso álcool, mobilizam um conjunto de representações fundamentais para a compreensão das maneiras de beber, do uso considerado abusivo de álcool e de seus efeitos nas relações familiares e profissionais.

O CRATOD é um centro de referência no estado de São Paulo, cujo objetivo é a implantação de políticas públicas na prevenção e tratamento dos transtornos decorrentes do uso considerado abusivo de álcool e de outras drogas.

O acolhimento dos usuários é feito de acordo com a região de moradia, de modo que o CRATOD atende segundo as demandas das regiões delimitadas pelas subprefeituras da Sé, Lapa e Moóca, à exceção de encaminhamentos feitos pela própria rede de saúde ou judiciário.

Ao chegar ao centro de referência, o usuário é acompanhado por uma equipe multiprofissional, geralmente formada por: profissionais das áreas de psiquiatria, uma equipe de enfermagem (enfermeiros, auxiliares e técnicos), assistência social, psicologia e nutrição.

Ele é recepcionado e suas queixas são ouvidas, compondo um histórico de sua trajetória: o início de sua relação de dependência, os motivos que o levaram a procurar o centro, ou se foi encaminhado para o serviço. Nesse momento, ele também é informado sobre o funcionamento da instituição.

Ainda no primeiro dia, é feita uma anamnese psiquiátrica detalhada, para a definição do tipo de tratamento que será aplicado. Além da consulta psiquiátrica, o usuário passa por entrevistas em cada área, para que seu atendimento seja ainda mais específico e individualizado. Com base nessas informações, é determinado o regime de tratamento do usuário e as atividades que ele irá praticar.

Após o acolhimento, o usuário passa a ser acompanhado semanalmente por um grupo chamado de os "acolhidos", isto é, aqueles usuários recepcionados no mesmo dia. 
No início do tratamento, geralmente, o usuário entra no chamado regime "intensivo", no qual ele precisa comparecer ao CRATOD todos os dias da semana, em, pelo menos, um dos períodos (manhã ou tarde), participando de todas as oficinas disponíveis naquele horário. A intenção dessas atividades é a de "desviar" e "ocupar" a mente do usuário, de maneira a "afastá-lo" da situação de dependência.

Assim que a ingestão de bebidas alcoólicas cessa ou diminui significativamente, o usuário passa para o regime "semi-intensivo", no qual ele deve comparecer ao centro de duas a três vezes por semana; o foco principal é a manutenção desse controle, contando com sua participação em grupos de psicoterapia e em oficinas, tais como: arte terapia, fuxico, xadrez, música, memória, poesia, percussão, padaria e atividade física, que o usuário pode escolher de acordo com suas habilidades.

Foram realizadas entrevistas semiestruturadas, cujo roteiro compreendia os dados de identificação, tais como: nome, estado civil, idade, religião, escolaridade, número de filhos, ocupação, bem como questões sobre o uso do álcool, o alcoolismo e seu tratamento, com ênfase no momento em que o uso do álcool passou a ser um problema, e sobre seus efeitos nas relações familiares e profissionais.

Ao longo da pesquisa, observou-se que cinco mulheres frequentavam o grupo de psicoterapia, sendo que duas delas não o faziam toda semana. Assim, foram adotados os seguintes critérios de inclusão na pesquisa: mulheres que estavam na fase semi-intensiva do tratamento, participando do grupo de psicoterapia semanalmente, e com disposição de participar das entrevistas.

O número restrito de sujeitos - três mulheres - é um limite desta pesquisa. Isso se explica porque a questão do uso considerado abusivo de álcool entre mulheres ainda representa um tema de difícil abordagem, tendo em vista o estigma e os preconceitos que o cercam. Durante a pesquisa, enfrentamos alguns problemas para conseguir os depoimentos, pois duas mulheres se recusaram a falar sobre o consumo que faziam do álcool.

Todavia, por se tratar de uma pesquisa qualitativa que, segundo Minayo (1994, p.22): "trabalha com o universo de significados, motivos, aspirações, crenças, valores e atitudes, que corresponde a um espaço mais profundo das relações, dos processos e dos fenômenos que não podem ser reduzidos à operacionalização de variáveis", o número restrito de sujeitos não compromete a validade do material coletado.

Esta pesquisa é conduzida com base em uma perspectiva teórico-metodológica interpretativa e compreensiva, com o objetivo de se compreenderem as representações e os significados da saúde e da doença (Victora et al., 2000).

As entrevistas foram realizadas nas dependências do CRATOD, uma vez por semana, entre os meses de abril e junho, após a realização do grupo de psicoterapia, e tiveram uma duração de uma hora. As mulheres foram informadas dos objetivos da pesquisa e assinaram um Termo de Consentimento Livre e Esclarecido.

As mulheres entrevistadas são identificadas pelas iniciais de seus nomes, como forma de preservar o sigilo das informações, e têm as seguintes características:

- AG, 48 anos, solteira, formada em ciências econômicas, católica, funcionária pública;

- SR, 57 anos, divorciada e vive em união estável, possui magistério, espírita, mãe de dois filhos, dona de casa;

- MF, 51 anos, divorciada, formada no Ensino Médio, católica, mãe de cinco filhos, auxiliar de serviços gerais.

As entrevistas foram transcritas e analisadas destacando-se as representações e os significados sobre o uso do álcool e seus efeitos na vida familiar e profissional das mulheres em tratamento no CRATOD.

\section{Álcool, família e gênero: os sentidos da alcoolização entre mulheres em tratamento para o alcoolismo}

As representações sobre o uso do álcool para as mulheres entrevistadas assumem um aspecto particular, traduzindo, em larga medida, os efeitos desse uso no interior da esfera familiar, relacionado às relações de gênero vivenciadas dentro da família. 
É exatamente isso que revela uma delas, quando indagada sobre sua ocupação atual: "sou suposta dona de casa, que não gosta de fazer nada" (SR). Ou ainda, quando indagada sobre as consequências do uso considerado abusivo do álcool nas relações familiares: "Maternidade é uma coisa muito complicada [...] por mais que eu tente, eu sei que eu não sou mãe" (SR).

Ou ainda, quando ela expõe as consequências do uso de álcool sobre as relações com seus filhos:

\begin{abstract}
"Com os meus filhos, que eu fiz sofrer, com o meu menino, chegava atrasada na creche para pegar ele, [e] totalmente de fogo [...] Quer dizer, eu aprontava algumas mesmo [...] Agora, com minha menina já foi pior, como eu já não trabalhava, nada [...] ela que sofreu um pouco mais [...] ela que me via mesmo ficar de fogo, e no final, toda a minha agressividade, eu passei para ela. Então, sobrou mesmo para ela, maltratar, de cortar o cabelo dela, de falar: 'você não é minha filha". (SR)
\end{abstract}

Essas falas são emblemáticas na medida em que deixam entrever uma representação da mulher que faz um uso considerado abusivo do álcool como uma mulher que não "gosta de fazer nada" e que, portanto, não desempenha seu papel social de "mãe", que deve cuidar de seus filhos.

Ou seja, a mulher que bebe de maneira considerada abusiva comporta-se de maneira oposta à mulher considerada "honesta", isto é, aquela que cumpre seu papel social de "esposa" e "mãe", que cuida dos filhos, ao mesmo tempo em que zela pela ordem da casa, de maneira a que tudo permaneça em seu lugar.

Essa representação do uso do álcool confirma os achados em pesquisa anterior que conduzimos em grupos de Alcoólicos Anônimos (AA), localizados na Zona Leste da cidade de São Paulo (Campos, 2005, p.150), na qual encontramos um leque de representações que reforça a ideia de que "lugar de mulher é em casa", de maneira que o alcoolismo compromete o desempenho de sua responsabilidade no âmbito da família, isto é, de "dona de casa", que deve cuidar dos filhos.

Essa representação também remete à pesquisa que Garcia (2004) conduziu em grupos de Alcoólicos Anônimos (AA), localizados na cidade de Niterói, Estado do Rio de Janeiro, onde, para os membros do grupo: "para a mulher, o ato de beber em ambiente público, não importando a modalidade, constitui transgressão, reconhecida pela categorização mulheres que bebem" (2004, p.155, grifos do original).

Embora não devamos fazer uma interpretação unívoca dessas falas, observa-se que elas traduzem, em larga medida, a representação da mulher cujo lugar por excelência é a casa. Assim, apesar de algumas delas expressarem sinais de inconformismo em relação à suposta submissão da mulher nas relações familiares, o conjunto dos relatos enfatiza o sofrimento da mulher que não se reconhece como aquela que deve zelar pela ordem da casa e cuidar dos filhos.

Em estudo sobre as relações de gênero e violência em grupos populares, Fonseca (2004) aponta que, entre as mulheres, associada ao papel de "esposa" e "mãe", também se encontra a possibilidade de construção da própria ideia de "honra", aqui "entendida como o esforço em enobrecer a própria imagem segundo as normas socialmente estabelecidas" (Fonseca, 2004, p.15). Ou seja, uma mulher "honrada" deve ser uma "mãe devotada" e uma "dona de casa" que zela pelos filhos e pelo marido.

É exatamente isso que revela uma das entrevistadas, ao narrar sobre o modo como o ato de beber não a impede de cumprir com os afazeres domésticos:

\footnotetext{
"Não era aquela pessoa que acordava e queria beber; acordava e ia cuidar dos meus afazeres [...] Não tinha aquela de 'não primeiro eu vou beber depois eu faço as coisas' ou 'vou comprar uma cerveja pra depois fazer o serviço', não [...] nunca pensei nisso, assim, quando eu acabava, eu queria beber, ai minha casa tava limpa, meu almoço tava feito, tava tudo pronto [...] nunca fui de beber na minha casa". (MF)
}

Na entrevista, MF deixa claro que bebia, mas somente após "cumprir" seu papel de mulher ("fazer o almoço", "deixar tudo pronto"), deixando a "casa limpa". Aqui, o uso do álcool é regido por 
uma lógica que remete às relações de gênero, vividas no interior da família, nas quais as relações sociais entre homens e mulheres são marcadas pela assimetria, hierarquia e pela desigualdade ${ }^{7}$.

Enquanto para o "homem alcoólico", o uso considerado abusivo de álcool provoca a deterioração "física" e "moral", comprometendo a responsabilidade moral no cuidado de si e de sua família, expressa na representação do "homem provedor" (Campos, 2005), as implicações desse uso para as mulheres entrevistadas são formatadas pela assimetria em relação ao homem, própria das relações de gênero vividas no interior da esfera familiar.

A representação do uso do álcool para as mulheres que participaram deste estudo incide diretamente sobre a ordem moral da família, definindo os sentidos da alcoolização marcados pelas relações de gênero nas quais estão envolvidas.

\section{"Mulheres que abusam do álcool": moralidades, sociabilidades e transgressões}

A categorização "mulher que abusa do álcool" possui um valor heurístico na medida em que permite entrever os sentidos da alcoolização feminina fundados nos valores próprios do contexto no qual as mulheres estão inseridas; ao mesmo tempo em que possibilita aprofundar a compreensão sobre o modo como o uso do álcool é marcado pelas transgressões das regras sociais que regem o uso de bebidas alcoólicas.

Em nossa sociedade, os bares são considerados um "contexto possível" para o uso do álcool, que possibilita a interação entre os seus frequentadores, favorecendo a construção de redes de relações sociais e a criação de vínculos a partir de regras que definem o ritmo de uma "alcoolização" controlada:

"Na época que eu bebia, eu só convivia com gente que bebia também, então não tinha problema nenhum". (AG)

Mas, se é certo que o bar é um contexto possível para o uso controlado do álcool, é necessário observar os modos diferenciais da alcoolização que envolvem os homens e as mulheres, marcados pelas relações de gênero. É assim que o bar é concebido como o espaço central para a produção e reprodução das relações sociais entre homens/trabalhadores (Guedes, 1997).

A frequência da mulher nesses espaços se dá de modo a ressaltar as diferenças entre os gêneros. Não por acaso, AG afirma que, em geral, ia sozinha ao bar:

\footnotetext{
"Chegava no bar sozinha, pedia uma cerveja e ficava de boa, ficava fazendo palavra cruzada se não tinha ninguém pra conversar, eu adorava fazer palavra cruzada! Eu ficava bebendo e fazendo [...] enquanto dava pra enxergar, né? Chegava uma hora que não dava pra ver mais nada [...], embaçava tudo".
}

O comportamento de AG evidencia que a frequência das mulheres ao bar é marcada por um comportamento muitas vezes solitário, deixando claro que o ato de beber, nesses espaços, pode consistir em uma transgressão marcada pelas relações de gênero.

Para as mulheres, o ato de beber socialmente implica não abusar da bebida, mantendo a rotina familiar e profissional:

\author{
${ }^{7} \mathrm{O}$ conceito de gênero \\ procura promover \\ a distinção entre 0 \\ dado e o construído, \\ isto é, entre o natural \\ e o sociocultural, \\ destacando que a \\ realidade é sempre uma \\ realidade construída, \\ particularmente aquela \\ que diz respeito às \\ relações entre o homem \\ e a mulher. Como aponta \\ Heilborn (2003, p.200): \\ "gênero é conceito \\ das ciências sociais que \\ se refere à construção \\ social do sexo [...] para \\ distinguir a dimensão \\ biológica da social. O \\ raciocínio que apóia essa \\ distinção se baseia na \\ idéia de que há machos \\ e fêmeas na espécie \\ humana, mas a qualidade \\ de ser homem e ser \\ mulher é realizada pela \\ cultura".
}


${ }^{8}$ Expressão usada para designar o estado de embriaguez.
“Eu trabalhava em um escritório de advocacia, normal [...] Às vezes, eu ia almoçar e voltava um pouco borratia ${ }^{8}$, mas nada que o chefe não sabia. Nada que atrapalhasse mesmo". (SR)

Ou, como AG afirma:

"Em casa, eu bebia bastante também. Arrumando a casa, fazendo comida. Eu fazia comida com a garrafa do meu lado."

Ou ainda:

"Nunca bebi no trabalho. Eu sempre ia ressacada, mas nunca bebia durante o trabalho, então não atrapalhava o rendimento nem nada. Eu podia sair do trabalho e depois beber, mas nunca durante o tempo de trabalho". (AG)

Os sentidos da alcoolização das mulheres apontam para a definição do beber abusivo como uma transgressão, que rompe com as normas que regem o beber socialmente aceito, conduzindo-as à perda do controle sobre o uso de bebidas alcoólicas e, consequentemente, sobre si mesmas:

"Eu tava bebendo como todo mundo, normal, mas tinha um momento, que não sei qual é até hoje, e às vezes eu acho que jamais vou descobrir [...] que era aquele ponto que eu já era [...] Aí, já era [...] eu perdia tudo, [perdia] o controle". (AG)

Isso fica evidente também na fala de AG sobre o modo como "abusava" do álcool:

"Minha irmã, quando eu bebia, ela falava: 'ai você tá insuportável, não dá pra falar com você direito' e, quando eu não bebia, ela falava: 'ah, agora sim, você tá maravilhosa, assim da pra conversar com você' [...] então, quando eu abusava, tinha um certo atrito, mas assim, ela me controlava. [...] Tinha vezes que ela saia comigo e me falava: 'quando chegar sua cota eu vou te avisar' [...] aí eu falava pra ela: 'então você me avisa que eu paro'. Então, a gente andava fazendo assim nas festas [...] Mas, aí eu ia dormir [...] não ficava enchendo o saco de ninguém [...] a coisa mais chata é bêbado [...] Deus me livre".

O uso "abusivo" do álcool deteriora as relações entre AG e seus familiares, levando-a a uma espécie de insulamento, que dificulta a relação com sua irmã, exigindo que esta a controle.

A representação do uso do álcool como "perda de controle" evidencia os modos diferenciais da alcoolização entre homens e mulheres, bem como a tensão com os valores que regem o universo sociocultural no qual as mulheres estão inseridas, particularmente da "família" e do "trabalho".

A "família" e o "trabalho" operam como valores fundamentais que ordenam e dão sentido ao mundo social. Nesse sentido, perder o controle sobre o álcool é, sobretudo, perder a qualidade moral de ser "mãe", "dona de casa" e "trabalhadora". 


\section{Acusação e diagnóstico no tratamento do alcoolismo}

As representações sobre o uso do álcool das mulheres entrevistadas, como "uso abusivo" e "perda de controle", ligam-se aos valores morais que formatam o universo sociocultural no qual elas estão inseridas, denotando um modo próprio de conceber a alcoolização, regido pelas relações de gênero.

Nesse sentido, essas mulheres não se reconhecem como "alcoólatras", no sentido médico do termo, mas sim que perderam o limite sobre as bebidas alcoólicas. É exatamente isso que revela MF quando indagada sobre a maneira que fazia uso do álcool:

\footnotetext{
“Eu comecei assim, saía do serviço com as amigas e tomava. No início era um suco, depois vai pra cerveja [...] Aí você não pensa que você é alcoólatra, você bebe uma vez por semana. Você não é alcoólatra, você bebe cerveja [...] Alcoólatra pra mim era aquele que tomava vodca; aquela pessoa que acordava e tomava pinga [...] Quando eu fui ver eu já tava bebendo no sábado, ao invés de só na sexta. Eu já tava bebendo no sábado, já tava bebendo no domingo. Na segunda não, porque de segunda a sexta era para trabalhar [...] aí eu não bebia. Em compensação, sexta à noite e sábado à tarde, eu marcava horário pra beber".
}

Nessa narrativa, MF deixa claro que não se reconhece como "alcoólatra", pois para ela o alcoólatra é aquele que ingere bebidas consideradas fortes, ao mesmo tempo em que acorda e já bebe "pinga". Em outras palavras, evidencia-se aqui o sentido social do uso do álcool, de modo que o ato de beber é reconhecido como um momento de lazer, que não compromete as atividades profissionais, diferenciando-se do "beber compulsivo", que conduziria à "dependência do álcool", própria do alcoólatra.

Opera-se, assim, uma distinção fundamental entre o "beber social", regido pelas regras do bem beber, e o "beber compulsivo", categoria médico-normativa, que define o beber patológico como uma "dependência do álcool".

Essa distinção é fundamental para a definição da representação do uso considerado abusivo do álcool como sendo uma doença. É isso o que vemos na entrevista com AG, quando ela afirma:

\footnotetext{
“No ano passado quando eu bebia, eu levei um susto. Eu bati a cabeça, e acordei com o travesseiro cheio de sangue, não tinha ninguém comigo e eu não lembrava de nada [...] eu fui para o hospital, e a médica de lá me falou pra procurar um psiquiatra. Aí, eu liguei e marquei pra ser atendida, e ela falou: 'Você nem volta pra ser atendida aqui; eu vou te atender lá no CRATOD, porque seu problema é alcoolismo'. Na verdade, eu ainda não sei bem se eu sou alcoólatra, mas é o que tá lá no meu prontuário".
}

A categoria "alcoolismo" é, assim, produto de um diagnóstico médico, que define o beber considerado abusivo como uma "dependência". Ora, não por acaso, AG se mostra desconfiada e demonstra não ter certeza se é realmente "alcoólatra", embora seja essa identificação que está em seu "prontuário".

As mulheres entrevistadas reforçam a distinção entre o "beber abusivo" e a "doença do alcoolismo":

"não tenho mesmo certeza se tenho essa doença [do alcoolismo] ou se é só o abuso mesmo. Mas, isso não é o que importa; o que importa é que há um descontrole com relação à bebida". (AG)

É assim que elas chegam ao CRATOD em busca de ajuda, por terem vivenciado a perda do controle sobre o álcool, pois "passaram do limite", que define o beber social, comprometendo a capacidade de cuidar de si mesmas: 
${ }^{9}$ A noção de categoria de acusação é entendida, aqui, no sentido atribuído por Velho (1999, p.57), compondo os chamados "sistemas de acusação", isto é, uma "estratégia mais ou menos consciente de manipular poder e organizar emoções, delimitando fronteiras".
“Você toma um golinho, toma mais um pouco. Você vai de uma bebida pra outra. Eu cheguei a dormir no ônibus! Fui até o ponto final; perdi a noção! Perdi a noção de beber". (MF)

É isso também o que aponta $A G$, quando indagada sobre o que a levou a buscar o tratamento no CRATOD, após o acidente que sofreu:

\begin{abstract}
“Eu me assustei e fui procurar essa médica. Ela falou: 'você precisa de tratamento'. Aí, tinha um colega que tava comigo, e ele que ficou contando as coisas pra médica. E ela me falou: 'Ele é seu anjo ou é a sua consciência externa?' Porque ele falava: 'ela abusa sim'. Aí, ela falou: 'vou te encaminhar pro CRATOD'. Não cheguei ao ponto de estragar nada. O problema era que eu chegava a gastar 100, 200 reais por semana em bebida e aí começa a atrapalhar mais no orçamento: o aluguel e as contas".
\end{abstract}

A noção de "abuso do álcool" opera como uma categoria de acusação", indicando o modo como AG transgride o conjunto de valores morais que compõe o universo sociocultural no qual ela está inserida. Ao afirmar que "ela abusa sim" do álcool, seu amigo aciona um sistema de acusações, baseado em uma lógica regida pelas relações de gênero, que demarcam os significados da alcoolização feminina, redesenhando, assim, os limites de sua identidade.

Não por acaso, a médica indaga se ele é sua "consciência externa", uma espécie de porta-voz da ordem moral, que aciona o sistema de acusações, dentro do qual AG é definida como uma "mulher que abusa do álcool", isto é, uma mulher que não cuida de si mesma e não cumpre suas "obrigações" nas esferas da família e do trabalho.

A categorização "doença do alcoolismo" não faz parte do repertório dessas mulheres, sendo atribuída a partir do diagnóstico médico-psiquiátrico:

“Dizem que essa doença não tem cura; é uma doença não é? Alcoolismo é doença, e não tem cura". (MF)

O tratamento oferecido pelo CRATOD, com a participação das mulheres nos grupos de psicoterapia e nas oficinas, possibilita, assim, a recuperação do controle sobre a própria vida, comprometido pelo uso considerado abusivo do álcool:
"Quando eu comecei o tratamento, eu percebi o quanto incomodava [no trabalho]. Eu percebi que eu tava incomodando antes, não era nada escancarado, mas eu tava incomodando [...] Quando eu comecei o tratamento, meus amigos falaram: 'olha, o que você ta fazendo é muito bom pra você'. Quando souberam que eu tava fazendo o tratamento, eu fui muito incentivada. [Na família], quando falei pra eles que comecei o tratamento, todo mundo ficou muito feliz comigo". (AG)

O tratamento, juntamente com o apoio dos amigos e dos familiares, representa a possibilidade de recuperar o controle sobre a ingestão das bebidas alcoólicas e, por essa via, o cuidado de si mesma, os vínculos familiares e profissionais:

\footnotetext{
"Meus filhos me dão a maior força. Eu falo pra eles [sobre o tratamento]. Eles já me trouxeram aqui antes do trabalho. Eles me dão a maior força". (MF)
} 
Ou ainda:

"Aqui [no CRATOD], pelo menos eu tenho pessoas que eu posso contar o que aconteceu comigo. Você se abre uma, duas vezes por semana". (MF)

É assim que as mulheres em tratamento no CRATOD encontram a possibilidade de recuperação, por meio do cuidado de si e do resgate dos vínculos familiares e profissionais, perdidos no tempo em que eram consideradas mulheres que abusavam do álcool.

\section{Considerações finais}

O ato de beber é um ato social, ligado aos códigos que regem o consumo de bebidas alcoólicas em um determinado contexto sociocultural (Castelain, 1990; Fabre-Vassas, 1989;).

As representações sobre o uso de álcool, construídas pelas mulheres entrevistadas, sintetizadas nas expressões "abuso do álcool" e "perda de controle sobre as bebidas", acionam um sistema de acusações baseado em uma lógica regida pelas relações de gênero, nas quais se revelam os modos diferenciais do consumo de bebidas alcoólicas entre homens e mulheres, por meio do qual elas são identificadas como "mulheres que abusam do álcool", isto é, mulheres que não cumprem suas obrigações sociais como "mães", "donas de casa" e "trabalhadoras".

A categoria médico-psiquiátrica "dependência do álcool" não abarca a complexidade das representações sobre o uso do álcool construídas pelas mulheres entrevistadas. Quando as mulheres falam que abusavam do álcool, elas falam, sobretudo, dos conflitos e dissabores enfrentados no meio social em que vivem.

As mulheres que fazem um uso considerado abusivo do álcool buscam um tratamento que as ajude reconstruir um sentido sobre a experiência do beber, possibilitando o controle sobre a ingestão das bebidas alcoólicas, redesenhando, assim, os contornos de suas vidas: pessoal, familiar e profissional.

\section{Colaboradores}

Edemilson Antunes de Campos responsabilizou-se pela orientação da pesquisa, análise das entrevistas, redação e revisão final do artigo. Jéssica Gallante Reis responsabilizou-se pela realização, transcrição e análise das entrevistas.

\section{Referências}

ANCEL, P.; GAUSSOT, L. Alcool et alcoolisme: pratiques et représentations. Paris: L'Harmattan, 1998.

CAMPOS, E.A. Alcoolismo, doença e pessoa: uma etnografia da associação de exbebedores Alcoólicos Anônimos. 2005. Tese (Doutorado) - Programa de Pós-Graduação em Ciências Sociais, Universidade Federal de São Carlos, São Carlos. 2005.

. As representações sobre o alcoolismo em uma associação de ex-bebedores: os Alcoólicos Anônimos. Cad. Saude Publica, v.20, n.5, p.1379-87, 2004

CARLINI. E.A. et al. II Levantamento domiciliar sobre uso de drogas psicotrópicas no Brasil - 2005. São Paulo: Centro Brasileiro de Informações sobre Drogas Psicotrópicas/ Departamento de Psicobiologia, Universidade Federal de São Paulo, 2006.

CASTELAIN, J.P. Vers une anthropologie du boire. In: CARO, G. (Org.). De I'alcoolisme au bien boire. Paris: L'Harmattan, 1990. v.1, p.70-2. 
FABRE-VASSAS, C. La boisson des ethnologues. Terrain, n.13, p.5-14, 1989.

FAINZANG, S. Curar-se do álcool: antropologia de uma luta contra o alcoolismo. Niterói: Intertexto, 2007.

. Ethnologie des anciens alcooliques: la liberté ou la mort. Paris: PUF, 1996.

FONSECA, C. Família, fofoca e honra: etnografia de relações de gênero e violência em grupos populares. 2.ed. Porto Alegre: Ed. UFRGS, 2004.

GARCIA, A.M. E o verbo (re) fez o homem: estudo do processo de conversão do alcoólico ativo em alcoólico passivo. Niterói: Intertexto, 2004.

GUEDES, S.L. Jogo de corpo: um estudo de construção social de trabalhadores. Rio de Janeiro: Ed. UFF, 1997.

HEILBORN, M.L. Articulando gênero, sexo e sexualidade: diferenças na saúde. In: GOLDENBERG, P.; MARSIGLIA, R.M.G.; GOMES, M.H.A. (Orgs.). O clássico e novo. Rio de Janeiro: Fiocruz, 2003. p.197-208.

JELLINEK, E.M. The disease concept of alcoholism. New Haven (Connecticut): Hilhouse Press, 1960.

JODELET, D. As representações sociais. Rio de Janeiro: Ed. UERJ, 2001.

LOPES, A.D.; MAGALHÃES, N. A bóia da prevenção. Rev. Veja, n.36, p.86-93, 2009.

MENÉNDEZ, E. El proceso de alcoholizacion: revision critica de la producion socioantropologica, histórica y biomédica en America Latina. Cuad. Casa Chata, n.57, p.61-94, 1982.

MINAYO, M.C.S et al. Pesquisa social: teoria, método e criatividade. Petrópolis: Vozes, 1994.

NEVES, D.P. Alcoolismo: acusação ou diagnóstico? Cad. Saude Publica, v.20, n.1, p.7-14, 2004

REIS, J.G. Percepções sobre o uso abusivo de álcool entre mulheres. 2009. Pesquisa (Iniciação Científica) - Programa Institucional de Bolsas de Iniciação Científica, Escola de Artes, Ciências e Humanidades, Universidade de São Paulo. 2009.

SOUZA, M.L.P.; GARNELO, L. Desconstruindo o alcoolismo: notas a partir da construção do objeto de pesquisa no contexto da saúde indígena. Rev. Latino-am. Psicopatol. Fundam., v.9, n.2, p.279-92, 2006.

VAILLANT, G.E. A história natural do alcoolismo revisitada. Porto Alegre: Artmed, 1999.

VARELLA, D. As mulheres e o álcool. Folha de São Paulo, p. E14, 23 mai. 2009. Caderno Ilustrada.

VELHO, G. Individualismo e cultura: notas para uma antropologia da sociedade contemporânea. 5.ed. Rio de Janeiro: Jorge Zahar, 1999.

VICTORA, C. et al. Pesquisa qualitativa em saúde: uma introdução ao tema. Porto Alegre: Tomo Editorial, 2000. 
CAMPOS, E.A.; REIS, J.G. Representaciones sobre el uso de alcohol: mujeres en tratamiento en un centro de referencia de la ciudad de São Paulo, Brasil. Interface Comunic., Saude, Educ., v.14, n.34, p.539-50, jul./set. 2010.

El objeto de este trabajo ha sido el de comprender las representaciones y los significados elaborados sobre el uso de alcohol por parte de mujeres en tratamiento en el Centro de Referencia de Alcohol, Tabaco y Otras Drogas (CRATOD), localizado en la ciudad de São Paulo. Para tanto se han realizado entrevistas semi-estructuradas con mujeres que hacen uso considerado abusivo del alcohol. Para estas mujeres las representaciones sobre el uso del alcohol están asociadas a las relaciones familiares, profesionales y de género que definen los modos de clasificación del uso del alcohol concebidos como socialmente aceptado y como abusivo y, por esta vía, accionan un sistema de acusaciones que incluye los valores proprios del universo socio-cultural en el que están ubicadas, identificándolas como "mujeres que abusan del alcohól"; esto es, mujeres que no cumplen sus obligaciones sociales en las esferas de la familia y del trabajo.

Palabras clave: Alcoholismo femenino. Género. Representaciones sociales. Uso abusivo de alcohol. 